\title{
Free triiodothyronine is a predictor factor of left ventricular remodeling in patients after myocardial infarction and primary reperfusion assessed by means of two-dimensional speckle tracking echocardiography
}

\author{
Joanna Wierzbicka-Chmiel ${ }^{1}$, Artur Chmiel ${ }^{1}$, Sławomir Rychlik ${ }^{1}$, Grzegorz Pifczyk ${ }^{1}$, Bogdan Marek ${ }^{1,2}$, Dariusz Kajdaniuk ${ }^{1,2}$ \\ 'Depertment of Cardiology and Endocrinology, Hospital Rybnik, Poland \\ ${ }^{2}$ Department of Pathophysiology and Endocrinology, School of Medicine in Zabrze, Medical University of Silesia, Katowice, Poland
}

Introduction. Left ventricular remodeling (LVR) is the most important consequence of acute myocardial infarction (AMI). The aim of the study was to assess the value of free triiodothyronine $\left(\mathrm{fT}_{3}\right)$ in the prediction of LVR after AMI and primary coronary angioplasty (PCI).

Methods. Seventy patients $(F / M=17 / 53,61 \pm 11$ years old) without recognized previous thyroid dysfunction and AMI were enrolled into the prospective observational study. Conventional and global longitudinal two dimensional speckle tracking echocardiography (LSTE) were performed 2 days (baseline) and 50 days after AMI. Thyroid function serum parameters $\left(T S H, \mathrm{fT}_{3}, \mathrm{fT}_{4}\right)$ were measured three times: before, 2 and 50 days after catheterization. Patients were divided into two groups according to the change of LSTE at 50 days follow up (increase I, decrease - II).

\begin{tabular}{|l|c|}
\hline \multicolumn{1}{|c|}{$\begin{array}{c}\text { Clinical characteristics } \\
(\mathbf{N}=\mathbf{7 0})\end{array}$} & $\begin{array}{c}\text { Mean } \pm \text { SD } \\
\text { Median (25Q-75Q) }\end{array}$ \\
\hline Age, years & $61 \pm 11$ \\
\hline Male gender, $\mathrm{n}(\%)$ & $53(76 \%)$ \\
\hline $\mathrm{BMI}, \mathrm{kg} / \mathrm{m}^{2}$ & $28.8(26.3-32.1)$ \\
\hline STEMI/NSTEMI, $\mathrm{n}(\%)$ & $27 / 43(39 \% / 61 \%)$ \\
\hline LV EF\% baseline & $52 \pm 10$ \\
\hline LSTE \% baseline & $-15.2 \pm 4.5$ \\
\hline eGFR, ml/min & $97 \pm 33$ \\
\hline hs Troponine T, ng/ml & $0.029(0.011-0.150)$ \\
\hline
\end{tabular}

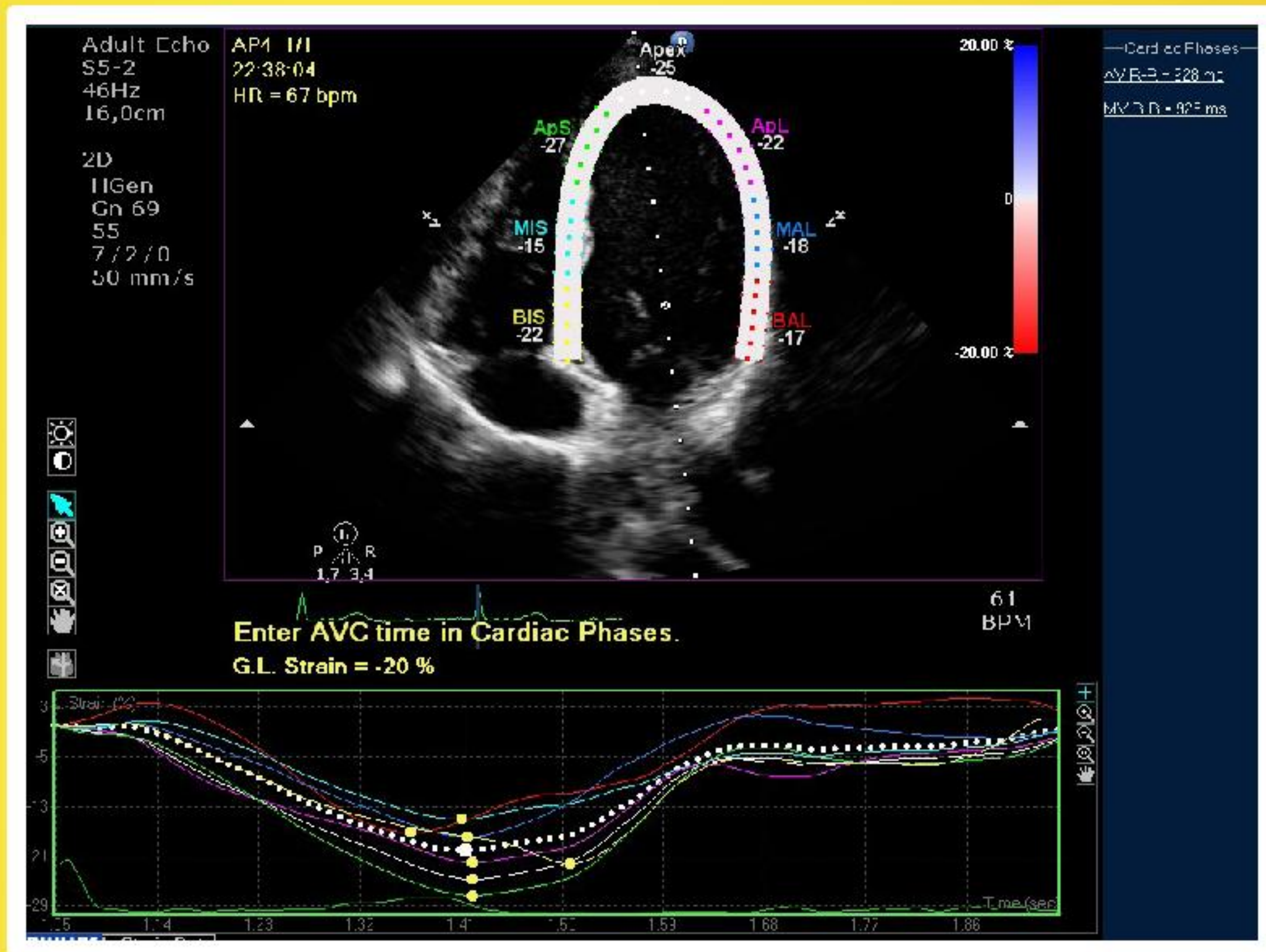

Two dimensional speckle tracking echo

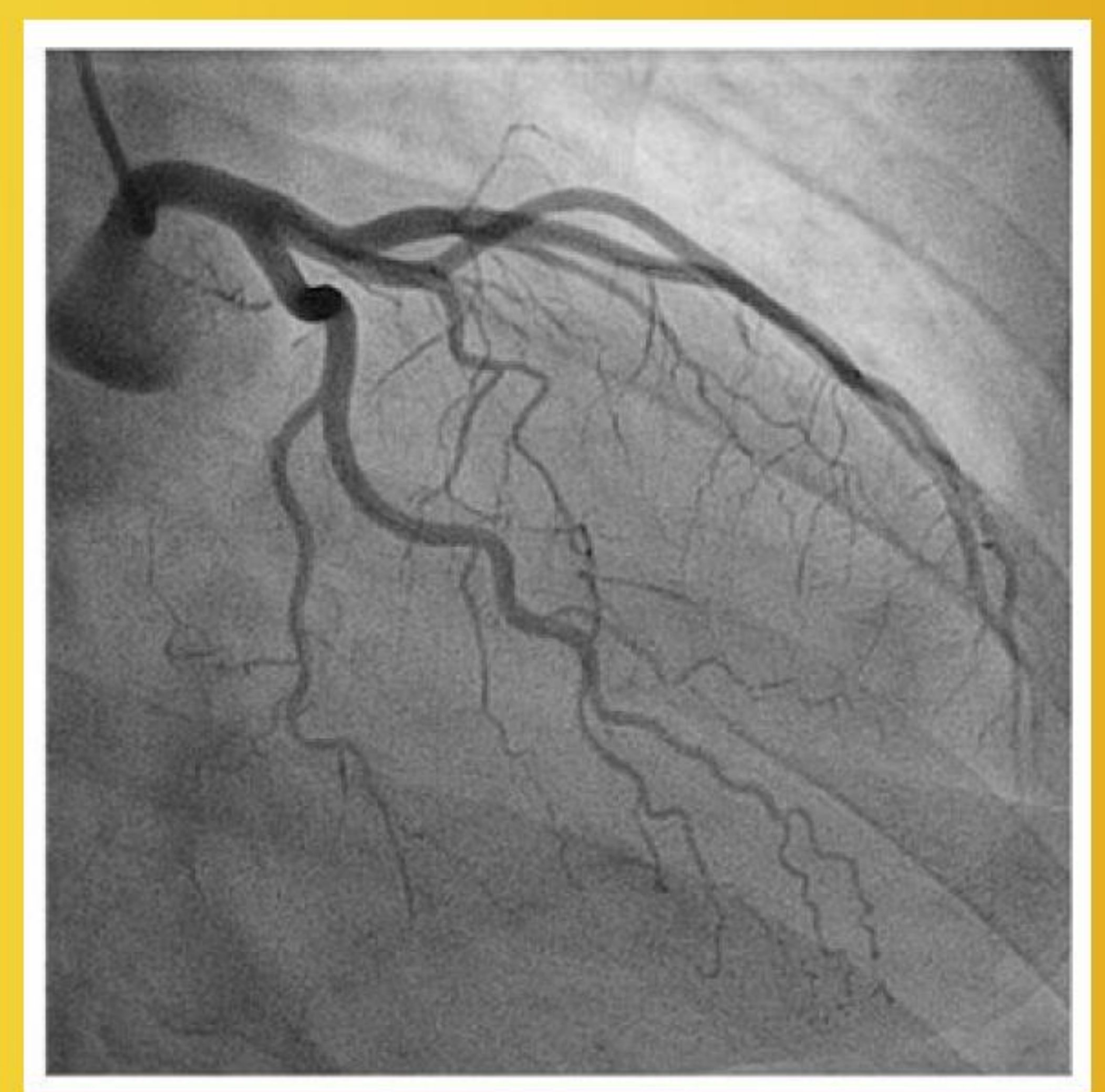

Normal left coronary artery

Results. At the baseline, both groups didn't differ in terms of $\mathrm{fT}_{3}$ concentration (mean difference $0.13 \mathrm{pg} / \mathrm{ml}$; $p=0.4$ ), left ventricular ejection fraction $(54 \% \pm 9$ v. $51 \% \pm 10 ; p=0.2)$ and global LSTE $(-17 \% \pm 4$ v. $-15 \% \pm 4 ; p=0.1)$. The difference between $\mathrm{fT}_{3}$ level between 2 and 50 days after $\mathrm{PCl}$ was a significant predictor of the change of LSTE (group $\mathrm{x}$ time interaction $\mathrm{p}=0.015$ ). According to the ROC analysis the increase of $\mathrm{fT}_{3}$ upper $0.28 \mathrm{pg} / \mathrm{ml}$ (sensitivity $69 \%$, specificity $54 \%$ ) was the most powerful predictor of the increase of LSTE after AMI.

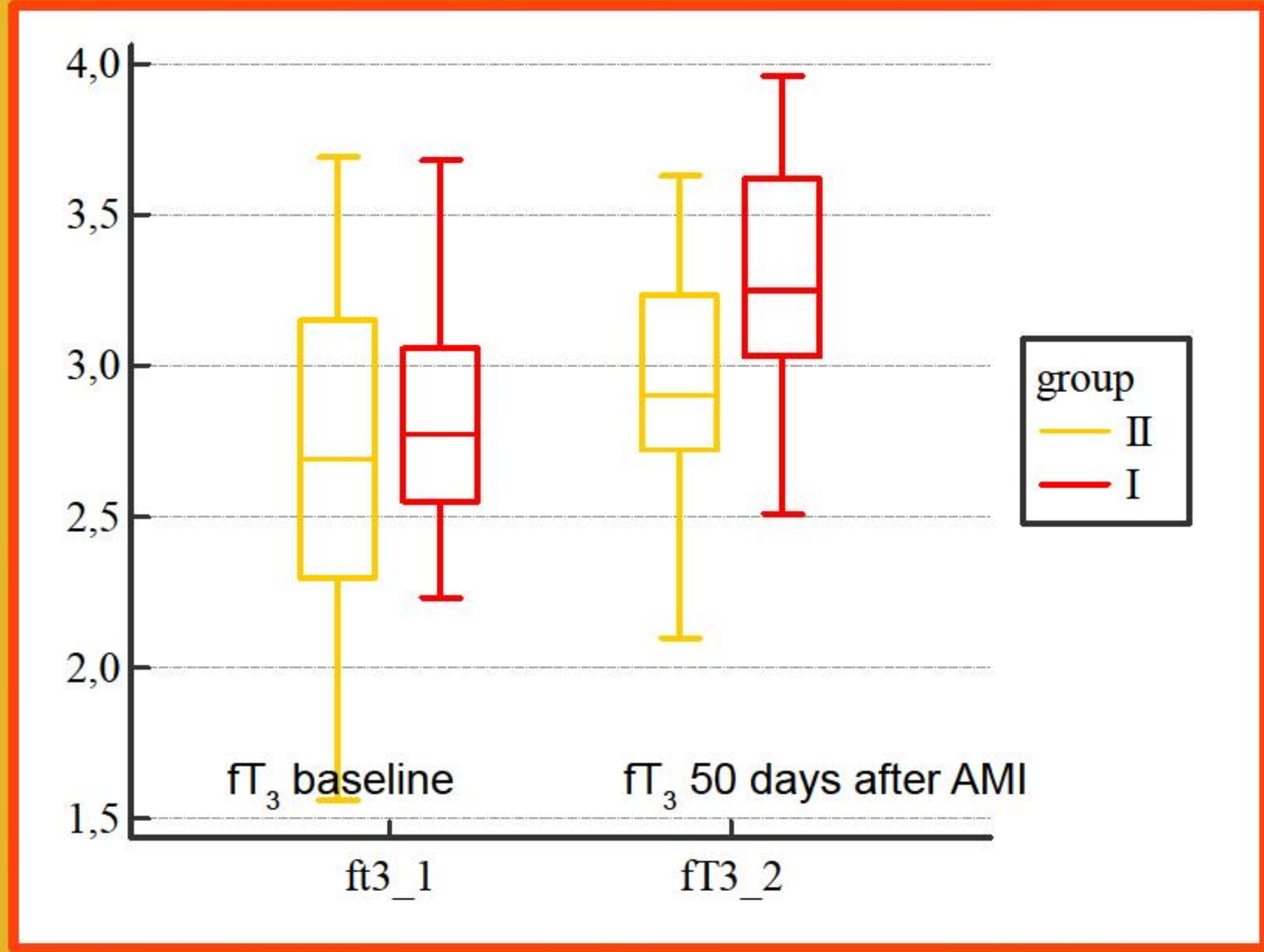

Change of $\mathrm{fT}_{3}$ in group I (increase of LSTE) and group II (decrease of LSTE)

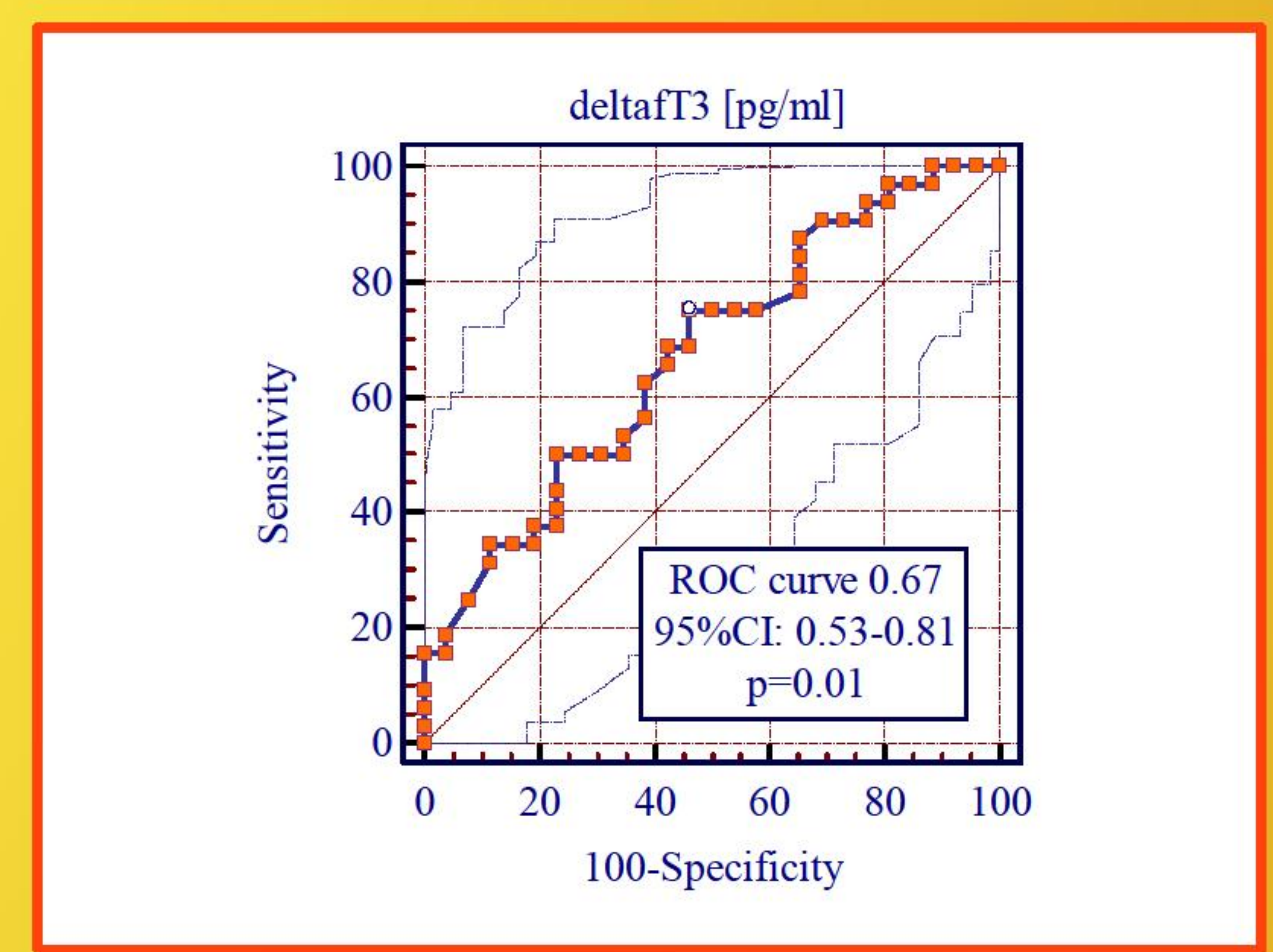

Receiver Operating Characteristic (ROC) curve of delta $\mathrm{fT}_{3}$ for presence LVR

Conclusion. The change of $\mathrm{fT}_{3}$ levels are closely associated with early LVR in patients with AMI and successful interventional treatment, hence might help to distinguish the patients endangered LVR. 